\title{
A facile approach for preparation of positively charged nanofiltration membranes by in-situ crosslinking between polyamide-imide and polyethylenimine
}

\author{
Aydın Cihanoğlu, Sacide Alsoy Altinkaya* \\ Department of Chemical Engineering, Izmir Institute of Technology, Gülbahçe Campus, 35430 Urla, İzmir, Turkey
}

\section{A R T I C L E I N F O}

\section{Keywords:}

Polyamide-imide

Polyethylenimine

In-situ crosslinking

Positively charged nanofiltration membrane

Phase inversion

\begin{abstract}
A B S T R A C T
Polyamide-imides (PAI) are attractive materials for membrane formation due to their high chemical and thermal stability. In this study, we report a facile approach for preparing positively charged nanofiltration (NF) membranes using a one-step process. Polyethylenimine (PEI) was dissolved in a coagulation bath and formed in-situ ionic crosslinking with PAI during phase inversion. The membranes were characterized by attenuated total reflectance Fourier Transform Infrared spectroscopy (ATR-FTIR), scanning electron microscopy (SEM), energy dispersive X-ray analysis (EDX), atomic force microscopy (AFM), contact angle and zeta potential measurements. The most positively charged membrane was obtained when the $\mathrm{pH}$ of the coagulation bath was adjusted to 10 . This membrane showed a significant decrease in contact angle and surface roughness and increase in the pure water permeability (PWP) compared to the plain PAI membrane. The salt rejection performance of the crosslinked PAI membrane was measured using $\mathrm{MgCl}_{2}, \mathrm{CaCl}_{2}, \mathrm{NaCl}$ and $\mathrm{Na}_{2} \mathrm{SO}_{4}$ salts. The rejection of $\mathrm{Mg}^{2+}$ and $\mathrm{Ca}^{2+}$ ions was found to be $95.6 \%$ and $90.2 \%$, respectively. The crosslinked membrane showed excellent chemical stability when stored in $\mathrm{HCl}$ solution at $\mathrm{pH} 3$ up to 7 days. Antifouling behaviour of the optimized membrane was tested using bovine serum albumin (BSA) and flux recovery ratio of the membrane was found to be $92.2 \%$ at the end of $3 \mathrm{~h}$ filtration. The results suggest that the positively charged PAI membranes crosslinked with PEI may have a potential in recovering valuable cationic metals from acid mine wastewater.
\end{abstract}

\section{Introduction}

Nanofiltration (NF) membranes fill the gap between ultrafiltration (UF) and reverse osmosis (RO) membranes and are used for separation of neutral and charged molecules in the range of $0.5-2 \mathrm{~nm}$ in diameter [1-6]. Positively charged NF membranes can exhibit high rejections for multivalent cations depending on their pore size and charge densities, hence, they can be used for recovery of valuable cationic macromolecules in biotechnology and pharmaceutical industries or removal of multivalent cations such as dyes and heavy metals from effluents in the paper and pulp, textile, nuclear, and automotive industries $[7,8]$.

Positively charged NF membranes are usually manufactured in the form of thin film composite (TFC) membrane through interfacial polymerization [9-19]. The main disadvantages of this method are the difficulty in controlling uniform growth of the selective layer over the surface and the possibility of changing the bulk structure of the support due to penetration of monomers. The second commonly used approach to prepare TFC NF membranes is to coat preformed polymer on the surface of a UF membrane by physical adsorption, electrostatic interactions or in some cases through a chemical reaction [20-28]. In both methods, the challenge is to obtain a very thin and stable selective layer in order to minimize the mass transfer resistance and maintain selectivity for a long period of time. NF membranes have also been manufactured by chemical or thermal post treatment of the integrally skinned asymmetric membranes. Economy's group designed positively charged flat sheet NF membranes by chemical post treatment of P84 copolyimide asymmetric membrane using branched polyethylenimine (PEI) [29]. Cui et al. [30] blended polyvinyl chloride with an amphiphilic copolymer of poly(methyl methacrylate-co-dimethyl aminoethyl methacrylate) (P(MMA-co-DMA)) and at the end of phase inversion, the membranes were immersed into p-xylene dichloride (XDC) solution to achieve crosslinking between XDC and tertiary amine units in the membrane. To obtain positively charged NF membranes in a single step without using any post treatment process, casting formulation has usually been adjusted to change the kinetics and thermodynamics of phase inversion. Yu et al. [31] mixed modified $\mathrm{Mg} / \mathrm{Al}$ hydrotalcite (mHT) with poly(ether sulfone) (PES) and pore former polyvinylpyrrolidone to fabricate loose NF membranes through nonsolvent

\footnotetext{
* Corresponding author.

E-mail address: sacidealsoy@iyte.edu.tr (S. Alsoy Altinkaya).
} 
induced phase separation (NIPS) method. The membrane showed high retention for dyes, reactive black 5 and reactive red 49, and low rejections for salts. Zhang et al. [32] used a positively charged polymercardo poly(arylene ether sulfone) with pendant tertiary amine groups (PES-TA) to prepare positively charged loose NF membranes in a single step. By changing the ratio of solvent (DMF) to co-solvent (THF) in the casting solution, the MWCO value of the membranes changed from 5555 to 1360. Yu et al. [33] blended modified silica spheres with polyethersulfone and pore former polyvinylpyrrolidone and tested the membranes for the dye/salt separation. These studies indicate that the positively charged NF membranes prepared in a single step with phase inversion are all in loose nanofiltration category with a MWCO greater than $1 \mathrm{kDa}$. The positive charge in the membranes was achieved with either fillers or a polymer modified with tertiary amine groups. In both approaches lengthy and complex procedures are applied which limit the scalability of the membrane production. On the other hand, the lack of a chemical bond between the filler and matrix polymer may cause a change in the long-term performance of the membranes due to leaching of the filler. These drawbacks indicate that there is still a need for simple protocols for an economical full-scale production of positively charged NF membranes.

Polyamide-imide (PAI), commercially known as Torlon, is a good candidate for membrane fabrication due to its superior mechanical properties, high thermal and chemical stability over a wide $\mathrm{pH}$ range. In literature, PAI based positively charged NF membranes were prepared at least in two steps $[34,35]$. First, a bare PAI membrane was formed using phase inversion process and then chemical post-treatment was applied on the prepared support layer at high temperature. In addition, various pore forming agents such as ethylene glycol (EG) [34], polyethylene glycol (PEG) with different molecular weights, polyvinylpyrrolidone (PVP) and $\mathrm{LiCl}$ [35] were added into the casting solution. Due to uncontrolled leaching of these agents, it is not easy to obtain long term stable NF membranes when a pore former was used.

In the present work, PAI based positively charged NF membranes were prepared in a single step by dissolving PEI in a coagulation bath at ambient temperature. In addition, no pore forming agent was used in the casting solution to obtain long term stable NF membranes. During the phase inversion process, chemical crosslinking occurs between amide group in the PAI and amine group of the PEI preventing back diffusion of PEI into water. The surface tension of the coagulation bath decreases in the presence of PEI, causing delayed demixing, hence, providing a dense skin layer production on the membrane surface. It has been hypothesized that the $\mathrm{pH}$ value is the driving force for the chemical crosslinking between PAI and PEI. To prove that, $\mathrm{pH}$ of the coagulation bath was adjusted to three different values. The membrane prepared at optimum $\mathrm{pH}$ was tested for its salt rejection performance and characterized in terms of its MWCO, morphology, elemental composition, charge, roughness and hydrophilicity of the surface, chemical stability and antifouling behaviour. To the best of our knowledge, a single step preparation of positively charged NF membranes with a MWCO less than $1 \mathrm{kDa}$ without using any pore former is being reported for the first time. This one-step preparation is less complicated and requires fewer steps than either interfacial polymerization or surface coating without any leaching risk.

\section{Experimental}

\subsection{Materials}

Polyamide-imide (PAI) (Trade name Torlon ${ }^{\circledast}, 4000$ T-LV) kindly supplied by Solvay Advanced Polymers, was used to obtain flat sheet substrates. N-methyl-2-pyrrolidone (NMP, anhydrous, greater than 99.5\%) was provided by Merck and used to dissolve PAI. Branched polyethyleneimine (PEI) with molecular weight $25 \mathrm{~kg} / \mathrm{mol}(\mathrm{kDa})$ and bovine serum albumin were purchased from Sigma-Aldrich. Neutral solutes of glucose (Merck), sucrose (Sigma-Aldrich), PEG 1000 (Sigma-

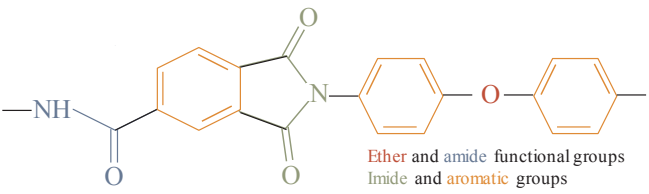

a) PAI

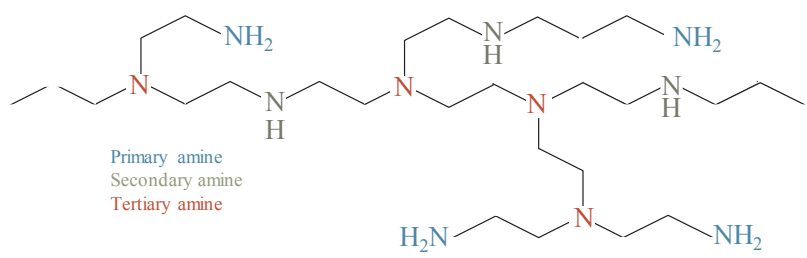

b) PEI

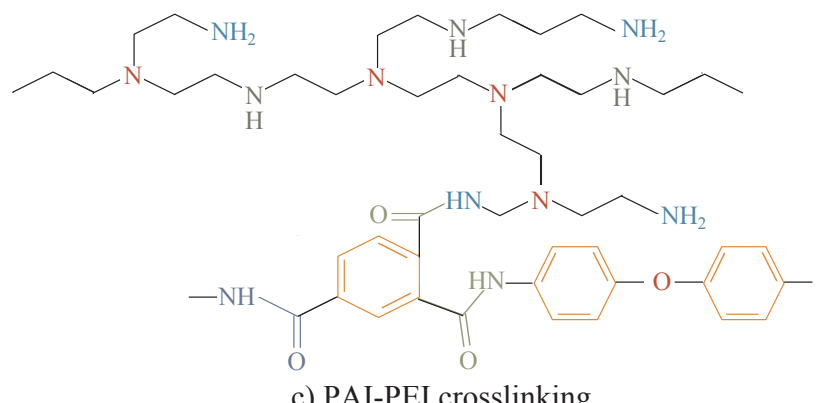

c) PAI-PEI crosslinking

Fig. 1. The chemical structures of PAI and PEI and the crosslinking reaction between PAI and PEI.

Aldrich) and PEG 600 (Fluka) were utilized to determine molecular weight cut-off (MWCO). $\mathrm{MgCl}_{2}$ (VWR), $\mathrm{CaCl}_{2}$ (Merck), $\mathrm{NaCl}$ (SigmaAldrich) and $\mathrm{Na}_{2} \mathrm{SO}_{4}$ (Merck) were used for determining the ion rejection capacity of the membrane. $\mathrm{HCl}$ with $37 \%$ purity (Sigma-Aldrich) was used to determine the chemical stability of the membrane. All the reagents were used without further purification.

\subsection{Preparation of the positively charged flat sheet membranes}

The positively charged flat sheet membranes were prepared by phase inversion method. PAI was first dried in a vacuum oven according to the Solvay drying procedure $\left(177^{\circ} \mathrm{C}, 3 \mathrm{~h}\right)$ to remove moisture. Dried polymer $(20 \mathrm{wt} \%)$ was dissolved in NMP (80 wt\%) solvent in a schott bottle. The mixture was stirred $(100 \mathrm{rpm})$ in an oil bath at $70^{\circ} \mathrm{C}$ for $18 \mathrm{~h}$ to obtain a homogeneous casting solution. Resulting solution was viscous and in order to eliminate air bubbles, solution was kept for $24 \mathrm{~h}$ without stirring, then, cast on a clean glass plate with the help of an automated film applicator (Sheen Instrument Ltd., model number: $1133 \mathrm{~N}$ ). The initial thickness of the cast membrane was adjusted by a four-sided applicator with a gap size of $200 \mu \mathrm{m}$. Following casting, the glass plate was immediately immersed into the coagulation bath including $0.5 \mathrm{wt} \%$ PEI and kept in the bath for $18 \mathrm{~h}$. The $\mathrm{pH}$ of the coagulation bath was adjusted to three different values, acidic $(\mathrm{pH}=4)$, neutral $(\mathrm{pH}=7)$ and basic $(\mathrm{pH}=10)$. The membranes prepared in acidic, neutral and basic coagulation baths were coded as PAI-PEI_pH 4, PAI-PEI_pH 7 and PAI-PEI_pH 10, respectively. The prepared membranes were then rinsed several times using deionised (DI) water to remove loosely bound crosslinking agent (PEI), and finally stored in DI water at $4{ }^{\circ} \mathrm{C}$ (refrigerator) until further tests.

\subsection{Nanofiltration experiments}

The filtration performance of the membranes was carried out using a dead-end cell filtration system with a cell volume of $10 \mathrm{~mL}$ and an effective surface area of $4.1 \mathrm{~cm}^{2}$ (Millipore, Amicon Stirred Cell 8010). 


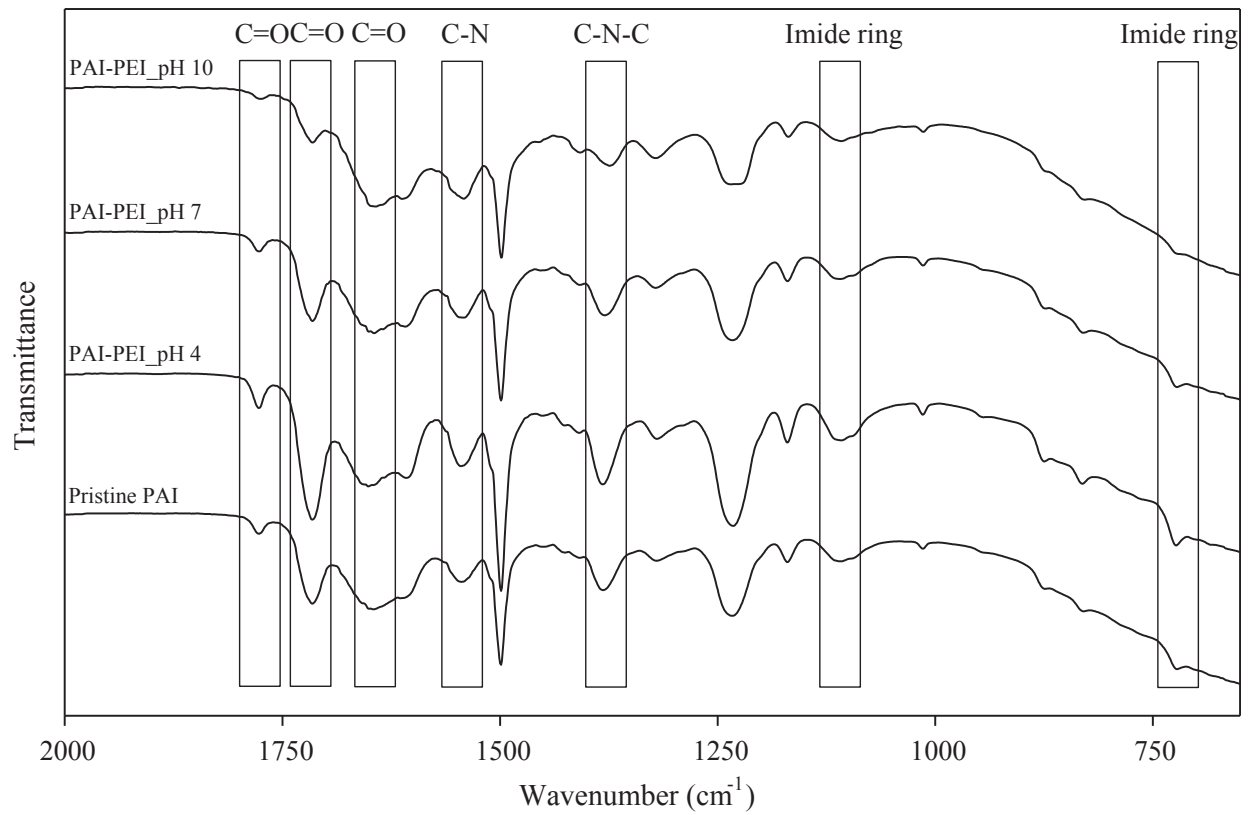

Fig. 2. ATR-FTIR spectra of uncrosslinked (pristine PAI) and crosslinked PAI membranes (PAI_PEI) at acidic, neutral and alkaline pH values.

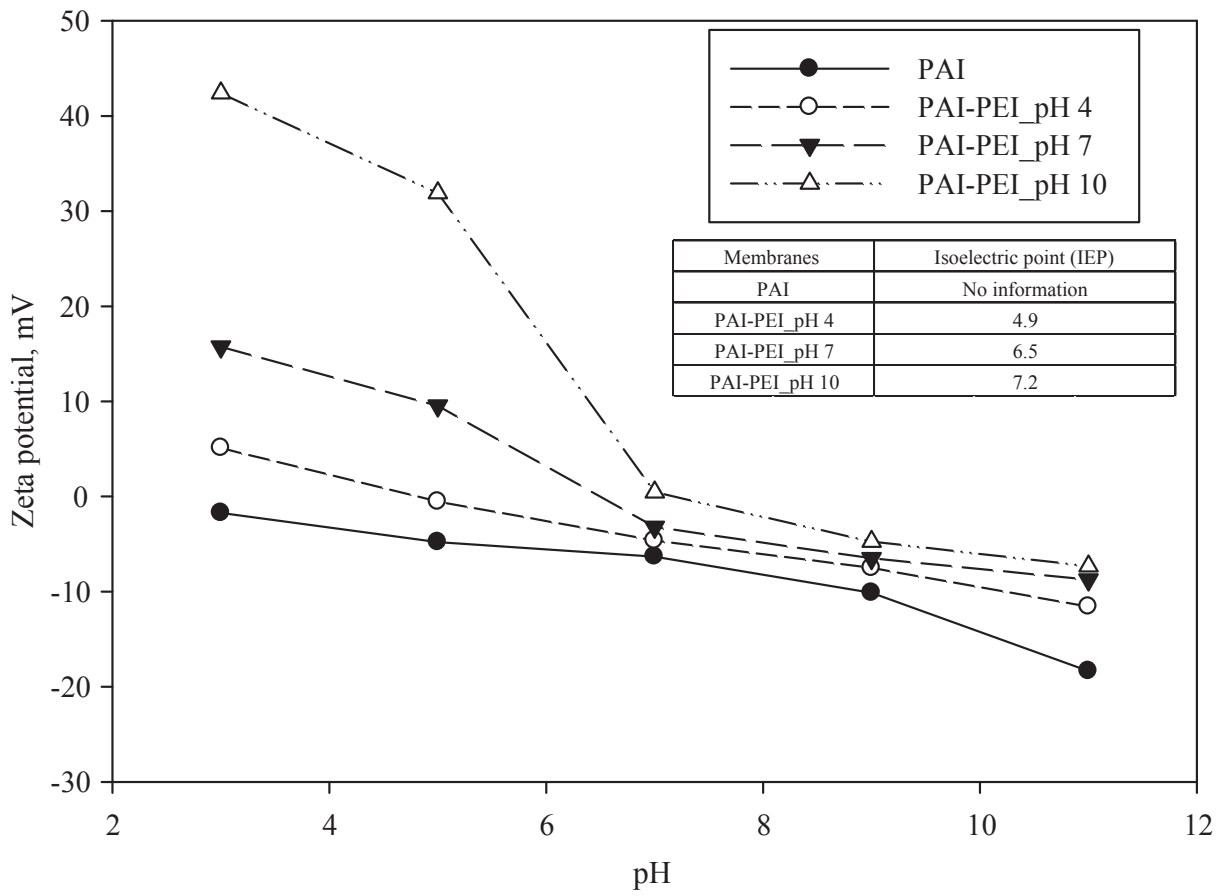

Fig. 3. Zeta potential as a function of $\mathrm{pH}$ for uncrosslinked (pristine PAI) and crosslinked PAI membranes (PAI_PEI) at acidic, neutral and alkaline pH values.

Each membrane was compacted at a pressure of $2.5 \mathrm{bar}$ for $1 \mathrm{~h}$ prior to any filtration test to ensure steady state conditions. Then, water was filtered at 2 bar and the volume of collected permeate was recorded for specific time intervals by reading weight of water from digital balance. The volumetric flux of water was calculated from the slope of the permeate volume vs. time graph and converted to hydraulic permeability (PWP) using following equation:

$P W P=\frac{\Delta V}{A \Delta t \Delta P}$

where $\Delta \mathrm{V}$ is the volume of permeated water $(\mathrm{L}), \mathrm{A}\left(\mathrm{m}^{2}\right)$ is the membrane area, $\Delta \mathrm{t}(\mathrm{h})$ is the permeation time and $\Delta \mathrm{P}$ (bar) is the transmembrane pressure difference applied through the membrane.
In rejection experiments, $1 \mathrm{~g} / \mathrm{L}$ aqueous solution of each neutral molecule was used instead of pure water. The solutes were filtered under the transmembrane pressure of 2 bar and the concentrations of permeate, retentate and feed solutions were measured by Rudolph J357 Automatic Refractometer. To determine the monovalent and divalent ion rejection capacity of the membrane, $1 \mathrm{~g} / \mathrm{L}$ salt solutions were filtered at $\mathrm{pH} 3$ under the transmembrane pressure of 2 bar. The concentration of permeate, retentate and feed solutions were measured by Dionex ICS-5000 ${ }^{+}$Ion Chromatography (IC). The percentage of solute rejection was calculated using the equation: 

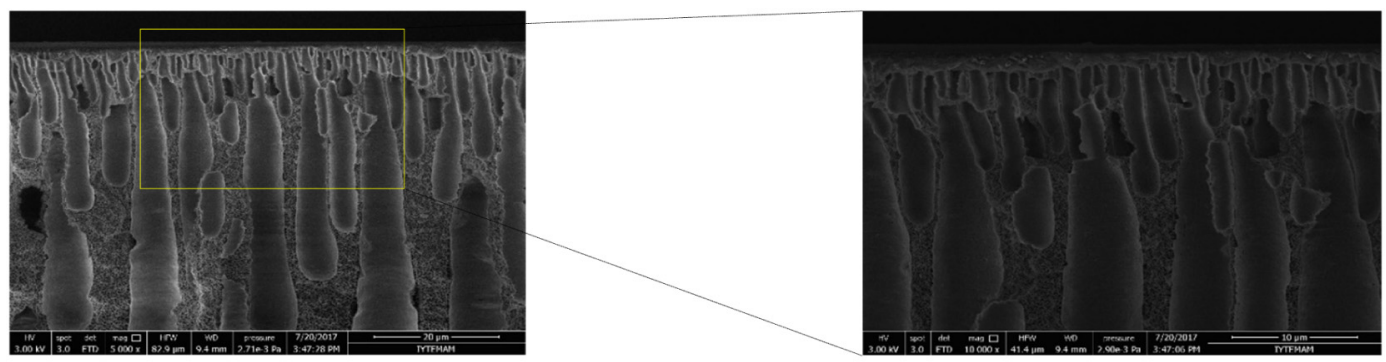

a) PAI
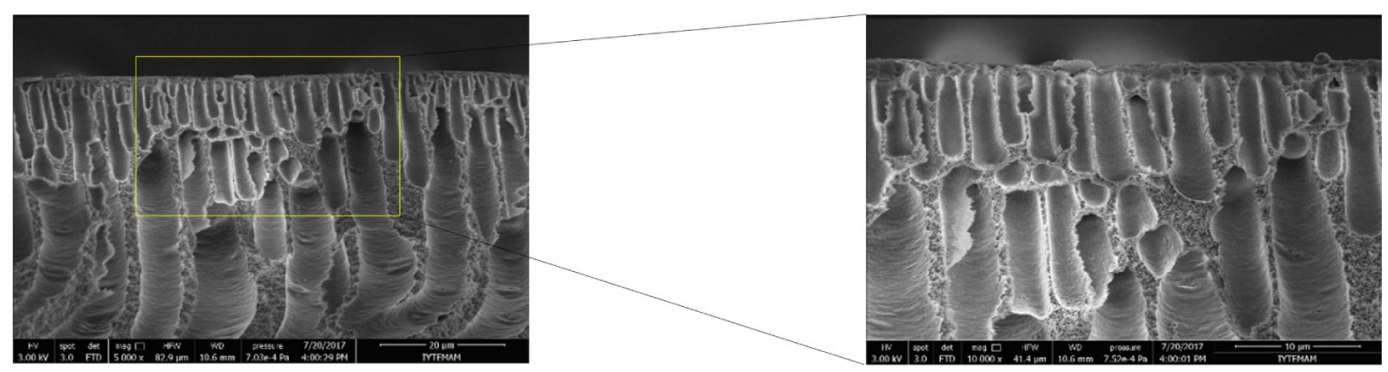

b) PAI-PEI_pH 4
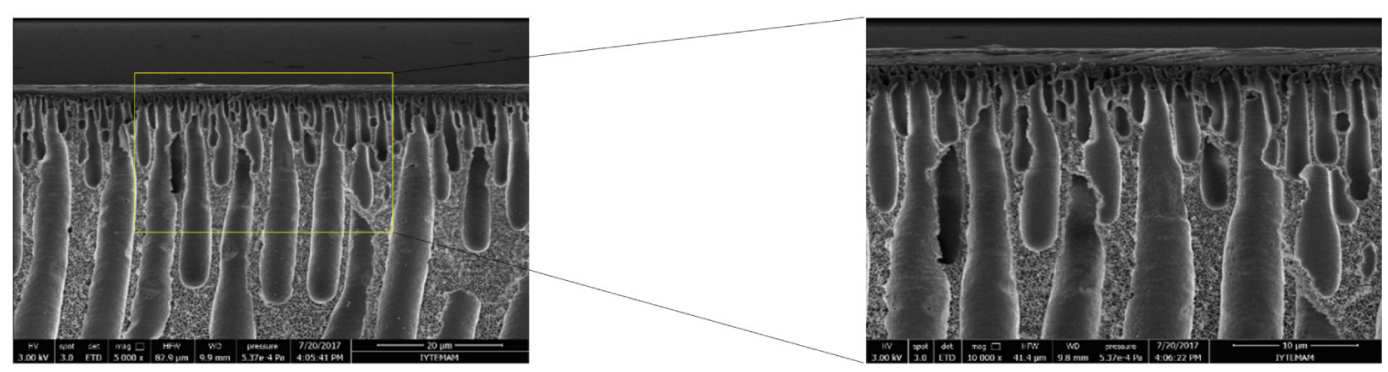

c) PAI-PEI_pH 7
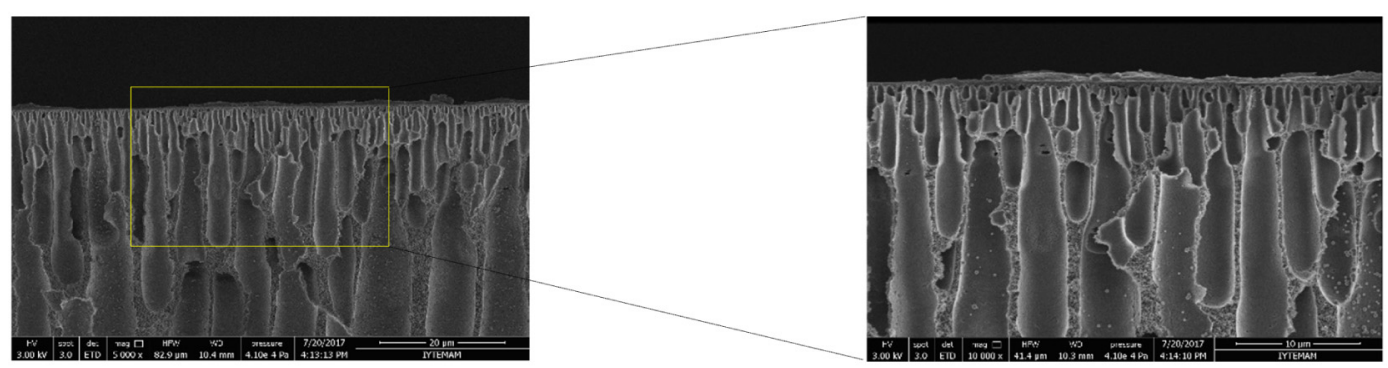

d) PAI-PEI_pH 10

Fig. 4. Cross-sectional SEM images of uncrosslinked (pristine PAI) and crosslinked PAI membranes (PAI_PEI) at acidic, neutral and alkaline pH values.

$R(\%)=\left(1-\frac{C_{p}}{\frac{C_{f}+C_{r}}{2}}\right) x 100$

where $C_{p}, C_{r}$ and $C_{f}$ are the concentrations of solutes in permeate, retentate and feed solution, respectively. The fouling behaviour of the membrane was tested using bovine serum albumin (BSA) as a model foulant. The concentration of the BSA solution was fixed at $1.0 \mathrm{~g} / \mathrm{L}$ and $\mathrm{pH}$ was adjusted to 4.8 (isoelectric point). Firstly, pure water flux $\left(\mathrm{J}_{\mathrm{W}}\right)$ of the clean membrane was measured with DI-water at 1 bar for $30 \mathrm{~min}$. Then, the flux of BSA solution $\left(\mathrm{J}_{\mathrm{P}}\right)$ passing through the membrane at 1 bar for $1 \mathrm{~h}$ was measured. The fouled membrane was washed with DIwater in static condition for $15 \mathrm{~min}$ and pure water flux $\left(\mathrm{J}_{R}\right)$ of the washed membrane was remeasured. Filtration and washing cycle was repeated for 3 times. The flux recovery ratio (FRR), total fouling (Rt), reversible fouling ( $\mathrm{Rr}$ ) and irreversible fouling (Rir) ratios were calculated using Eqs. (3)-(6).

$\operatorname{FRR}(\%)=\frac{J_{R}}{J_{W}} \times 100$

$R_{t}(\%)=\left(1-\frac{J_{P}}{J_{W}}\right) x 100$

$R_{r}(\%)=\left(\frac{J_{R}-J_{P}}{J_{W}}\right) x 100$

$R_{i r}(\%)=\left(\frac{J_{W}-J_{R}}{J_{W}}\right) x 100$

During all solute filtration experiments, the magnetic stirrer was used to provide vigorous mixing and reduce concentration polarization which may otherwise occur on the membrane surface. The experiments 


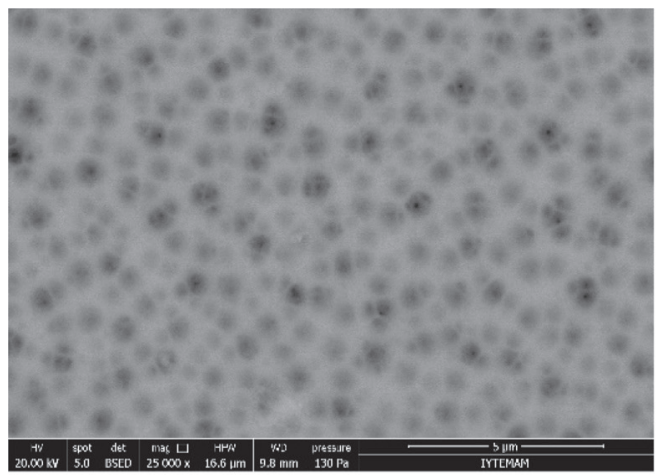

PAI

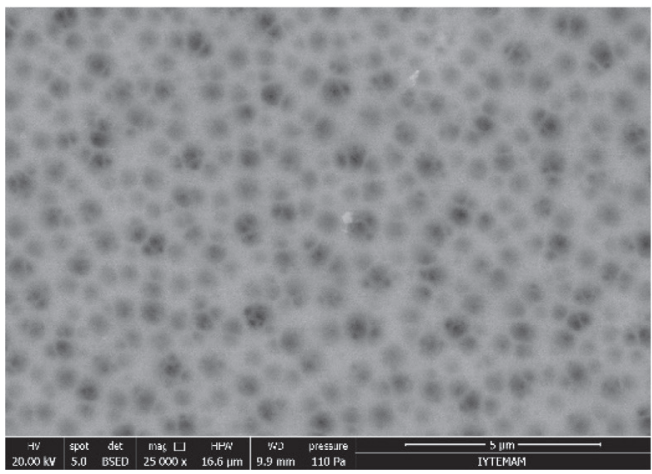

PAI_PEI_pH 7

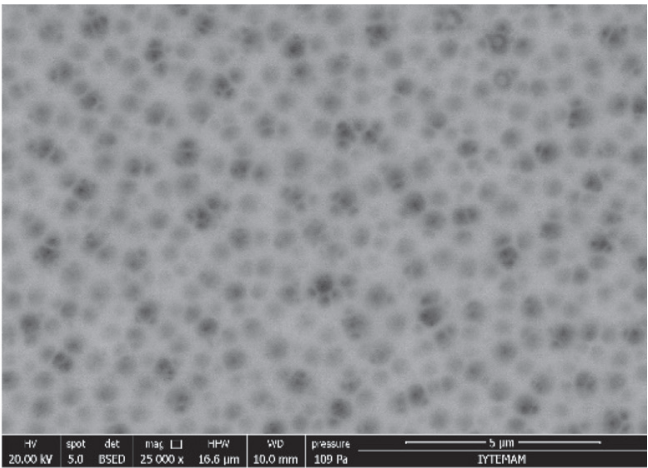

PAI_PEI_pH 4

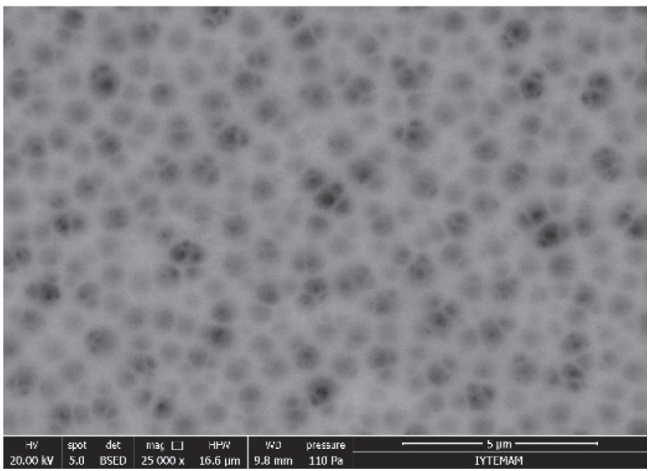

PAI_PEI_pH 10

Fig. 5. Surface SEM images of uncrosslinked (pristine PAI) and crosslinked PAI membranes (PAI_PEI) at acidic, neutral and alkaline pH values.

Table 1

EDX analysis of the uncrosslinked PAI and crosslinked PAI membranes with PEI at $\mathrm{pH} 10$.

\begin{tabular}{lllll}
\hline Membranes & C (wt \%) & N (wt \%) & O (wt \%) & C/N \\
\hline PAI & 67.11 & 10.19 & 22.70 & 6.59 \\
PAI-PEI_pH 10 & 61.16 & 16.31 & 22.54 & 3.75 \\
\hline
\end{tabular}

were carried out at room temperature.

\subsection{Stability of the membranes}

The structural stability of the membrane was examined by storing in $\mathrm{HCl}$ aqueous solution at $\mathrm{pH} 3$ up to 7 days under static condition in refrigerator. The PEG 1000 rejection of the membrane was measured before and after exposure to the $\mathrm{HCl}$ acid.

\subsection{Physical characterization}

\subsubsection{Membrane morphology}

The cross-section and surface of the membranes was characterized using a scanning electron microscope (SEM) (FEI Quanta 250 FEG). In order to obtain a cross-sectional view, the membrane was first immersed in liquid nitrogen, and then cut with a clean razor blade. Also, energy dispersive X-ray analysis (EDX) was performed using the same SEM device to determine elemental composition of the membrane surfaces. Before imaging and analysis, all membrane samples were coated with gold nanoparticles to increase the conductivity of the surface using Magnetron Sputter Coating Instrument.

\subsubsection{Membrane surface topology}

Surface roughness of the membranes was examined using atomic force microscopy (AFM) (MMSPM Nanoscope 8, Bruker). Membrane samples with an area of $2 \mu \mathrm{m} \times 2 \mu \mathrm{m}$ were scanned at a rate of $1 \mathrm{~Hz}$ using tapping mode in air at ambient temperature by using NCHV model tip (Bruker). Mean roughness $\left(R_{a}\right)$ and root mean square $\mathrm{Z}$ values $\left(R_{m s}\right)$ were measured to obtain the information about the surface topology in detail.

\subsubsection{Membrane surface chemistry}

The chemical crosslinking between imide group in PAI and amine group of the PEI was confirmed by Attenuated Total Reflectance Fourier Transformed Infrared Spectrometer (ATR-FTIR), (Perkin Elmer). ATRFTIR spectra were collected at ambient temperature over a scanning range of $2000-650 \mathrm{~cm}^{-1}$ with a resolution of $4.0 \mathrm{~cm}^{-1}$. The flat sheet membranes were dried in a vacuum oven (Memmert) at $25{ }^{\circ} \mathrm{C}$ prior to analysis.

\subsubsection{Membrane surface charge}

The surface charges of the pristine and modified membranes (zeta potential) were determined using streaming potential measurements with NanoPlus Micromeritics Instrument. The measurements were carried out in the presence of $10^{-3} \mathrm{M} \mathrm{KCl}$ electrolyte solution. To determine the isoelectric point (IEP) of the membranes, the measurements were performed at different $\mathrm{pH}$ values. The $\mathrm{pH}$ value of the electrolyte solution was adjusted using $0.5 \mathrm{M}$ hydrochloric acid ( $\mathrm{HCl}$ ) (SigmaAldrich) for acidic $\mathrm{pH}$ and $0.5 \mathrm{M}$ sodium hydroxide $(\mathrm{NaOH})$ (SigmaAldrich) for basic $\mathrm{pH}$. The Helmholtz-Smoluchowski equation was used to calculate the apparent zeta potential of membrane surface [36].

\subsubsection{Membrane hydrophilicity}

Contact angles of the pristine and crosslinked membranes were measured using Attension Optical tensiometer. Before measurement, membranes were dried in a vacuum oven (Memmert) at $25^{\circ} \mathrm{C}$. The dried membranes were fixed to a glass surface using double-sided tape. 

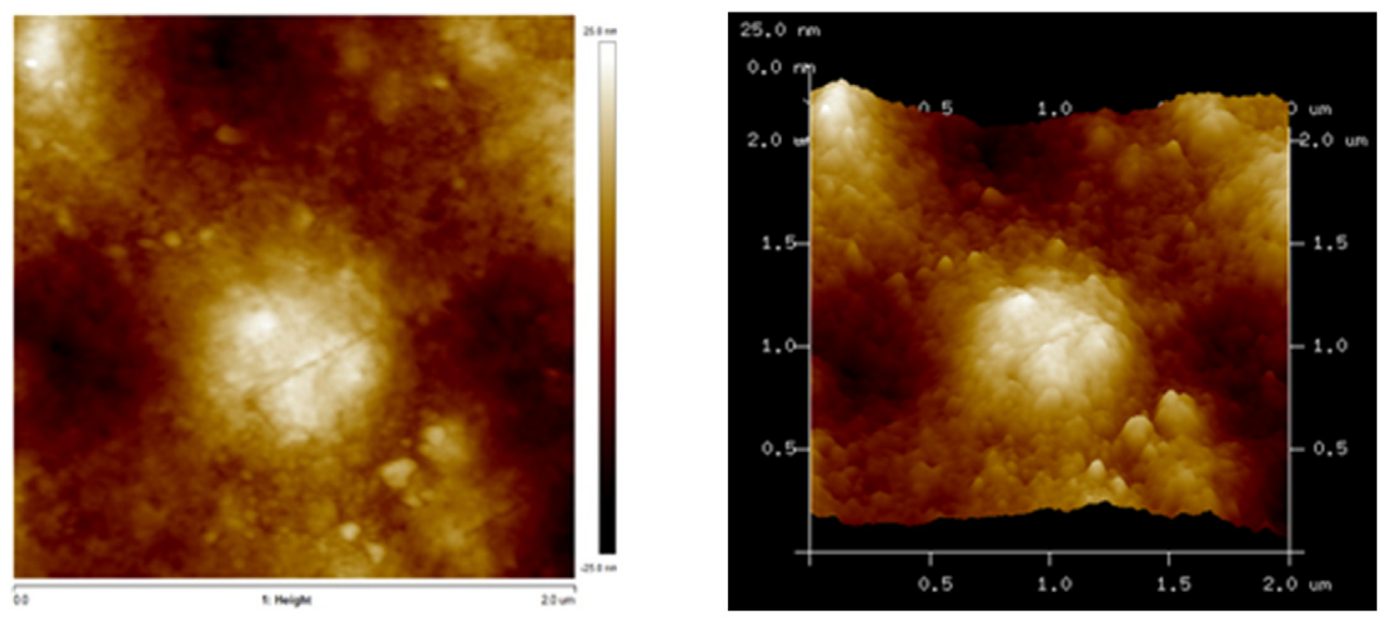

a) PAI
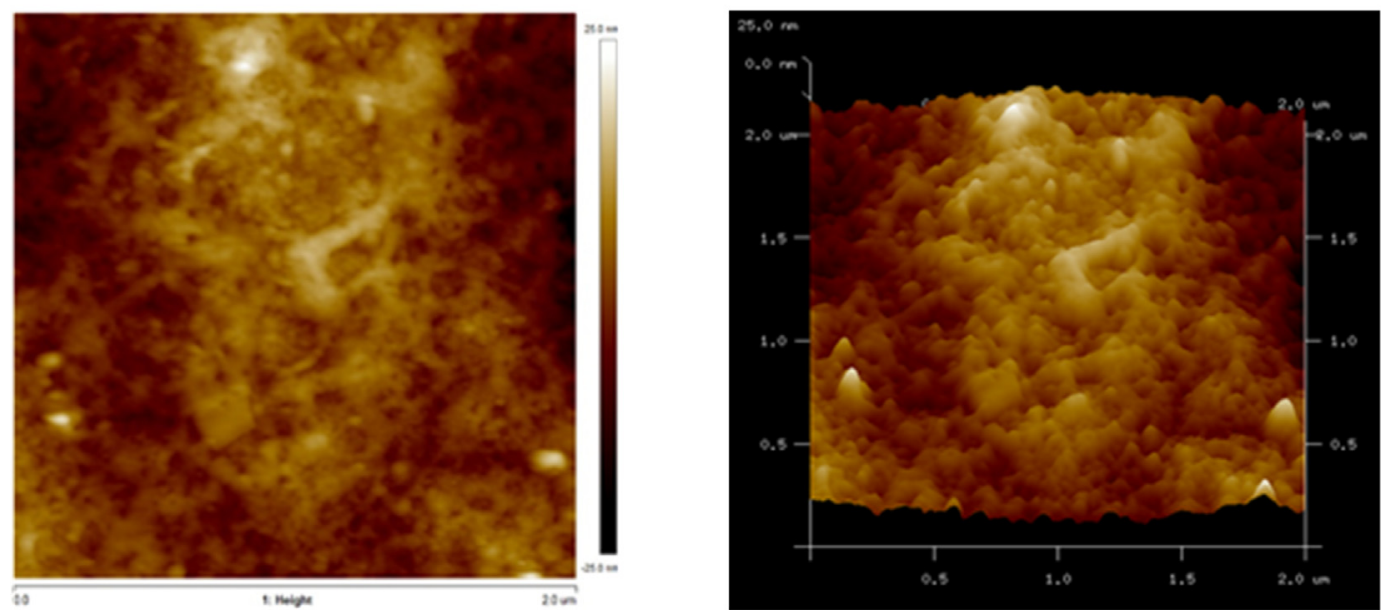

b) PAI-PEI_pH 10

Fig. 6. AFM images of uncrosslinked (pristine PAI) and crosslinked PAI membranes with PEI at pH 10.

Table 2

Surface roughness values of uncrosslinked and crosslinked PAI membranes with PEI at $\mathrm{pH} 10$.

\begin{tabular}{llc}
\hline Membranes & $\mathrm{R}_{\mathrm{a}}(\mathrm{nm})$ & $\mathrm{R}_{\mathrm{q}}(\mathrm{nm})$ \\
\hline PAI & 3.35 & 4.17 \\
PAI-PEI_PH 10 & 1.76 & 2.33
\end{tabular}

All measurements were carried out with $5 \mu$ l volume of deionized water droplet.

\section{Results and discussion}

\subsection{Characterization of membranes}

The PAI based positively charged flat sheet NF membranes were prepared in a single step by using a new approach. In this approach, positively charged polyelectrolyte PEI dissolved in a coagulation bath diffuses into PAI solution during immersion step of the phase inversion process. As shown in Fig. 1, chemical crosslinking occurs between imide groups in PAI and amine groups of PEI. The degree of crosslinking can be easily adjusted with the immersion time in the coagulation bath without any need for high temperature. It is hypothesized that the $\mathrm{pH}$ of the coagulation bath determines the degree of crosslinking and to prove this hypothesis, three different membranes were prepared by adjusting the $\mathrm{pH}$ to 4,7 and 10.

The chemical crosslinking between imide groups in PAI and amine groups of PEI was confirmed by ATR-FTIR measurement (Fig. 2). The pristine PAI membrane can be identified by the characteristic peaks belonging to imide groups at wavenumbers of 1777 and $1716 \mathrm{~cm}^{-1}$ (symmetric and asymmetric $\mathrm{C}=\mathrm{O}$ stretching, respectively), $1382 \mathrm{~cm}^{-1}$ (C-N-C stretching), 1108 and $722 \mathrm{~cm}^{-1}$ (imide ring) and the amide groups at wavenumbers of $1643 \mathrm{~cm}^{-1}(\mathrm{C}=\mathrm{O}$ stretching $)$ and $1542 \mathrm{~cm}^{-1}$ (C-N stretching of the $\mathrm{C}-\mathrm{N}-\mathrm{H}$ group). Fig. 2 demonstrates that as the $\mathrm{pH}$ of the coagulation bath is changed from 4 to 10 , the characteristic peaks for the imide group slowly decreases while the peaks for the amide group increases progressively. This result indicates more imide ring opening and higher degree of chemical crosslinking formed between amine and imide groups with the increased $\mathrm{pH}$ in the coagulation bath.

The surface charges of pristine and crosslinked membranes were determined by zeta potential measurement. As shown in Fig. 3, the pristine membrane (PAI) has a negative charge within the $\mathrm{pH}$ range of 3-11 due to deprotonation of the carboxyl groups. After chemical crosslinking with PEI, the surface charge of the PAI membranes was gradually directed towards the positive values as a result of protonation of the amine groups in the PEI. Also, isoelectric point (IEP) (embedded in Fig. 3) of the membranes shifted to higher $\mathrm{pH}$ values because of the amine groups attached to the membrane surface. The membrane 


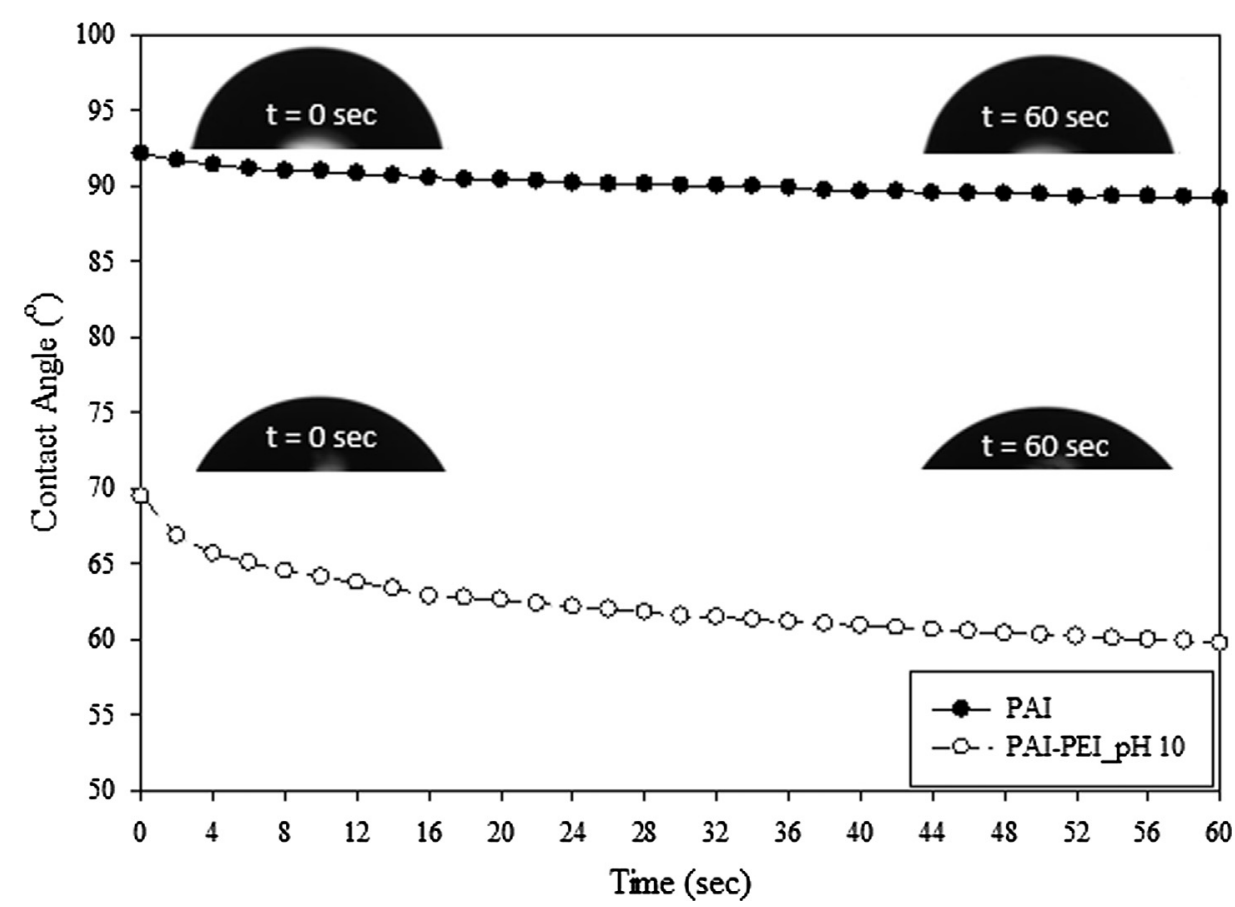

Fig. 7. Water contact angle of uncrosslinked and crosslinked PAI membranes with PEI at pH 10.

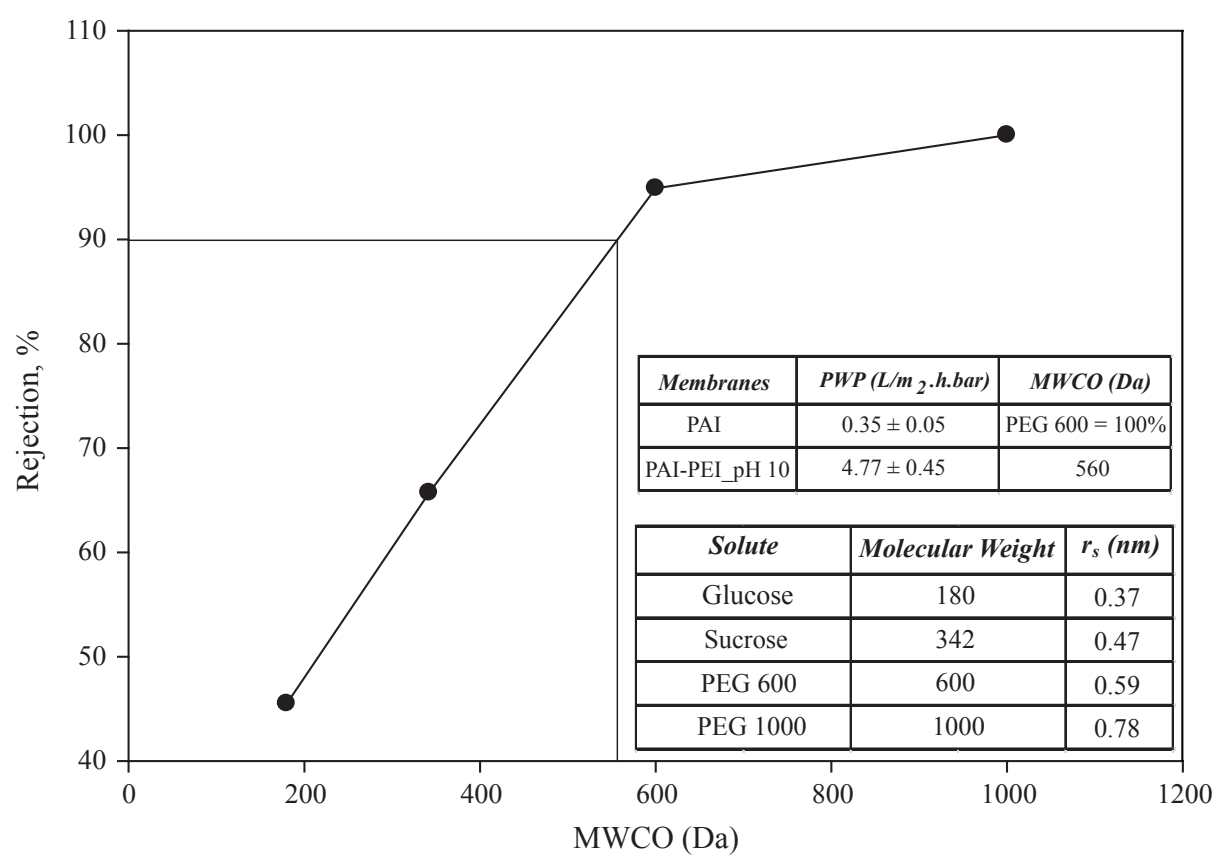

Fig. 8. The MWCO curve of the PAI membrane crosslinked with PEI at pH 10.

formed at alkaline pH, PAI-PEI_pH 10, has the highest positively charged group which indicates the highest degree of crosslinking achieved at this $\mathrm{pH}$. As the $\mathrm{pH}$ of the PEI solution shifted towards neutral and acidic values ( $\mathrm{pH} 7$ and $\mathrm{pH}$ 4), the amount of positive charge dramatically decreased. This simply proves our hypothesis about the $\mathrm{pH}$ dependent degree of crosslinking. From the zeta potential and ATR FTIR data, it can be concluded that the tendency of the imide ring opening is low in acidic and neutral $\mathrm{pH}$ values and the chemical crosslinking is favoured in alkaline rather than in acidic $\mathrm{pH}$.

The cross-section and surface morphologies of the membranes were characterized using SEM pictures. As shown in Figs. 4 and 5, a thin dense skin layer and finger like pores in the sublayer were observed for all the membranes. The bulk morphology of membranes prepared by phase inversion technique is influenced by the viscosity of the coagulation bath. Adding $0.5 \% \mathrm{PEI}$ into the coagulation bath or adjusting $\mathrm{pH}$ did not change the viscosity of the solution in the bath. That's why we could not see big differences between the cross-section SEM images of the uncrosslinked and crosslinked membranes prepared at three different $\mathrm{pH}$ values. Based on the results in Figs. 2-5, we have selected the membrane carrying the highest positive charge density, PAI-PEI_PH 10, as the optimum membrane. EDX analysis results in Table 1 indicated that amount of nitrogen in PAI-PEI_10 membrane is $60 \%$ higher than in pristine PAI membrane. This result further proved the occurrence of the ionic crosslinking between PAI and PEI. We have also compared surface 


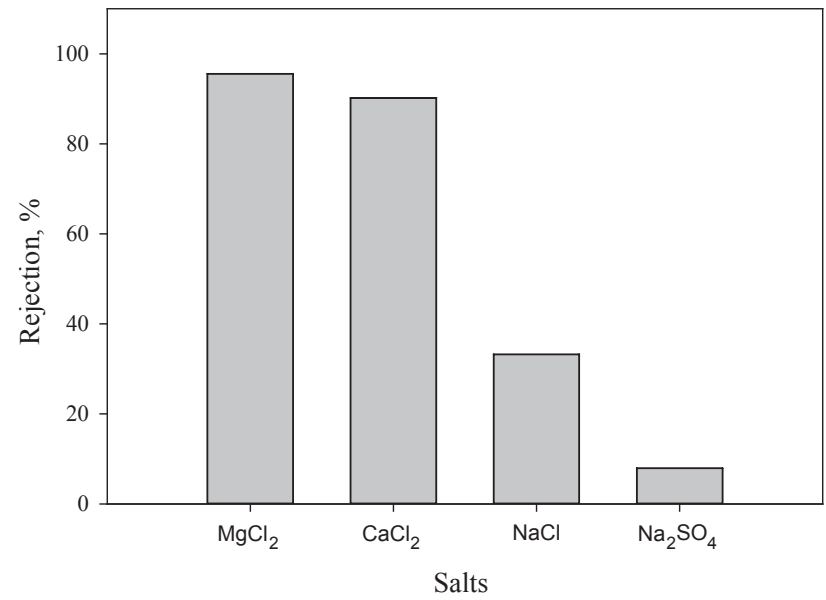

Fig. 9. Salt rejection performance of the PAI membrane crosslinked with PEI at pH 10.

properties, average pore size and salt rejection performances of the uncrosslinked and crosslinked PAI membranes.

AFM images in Fig. 6 showed that the surface roughness of the pristine PAI membrane is nearly 50\% higher than the PAI_PEI_pH10 membrane in terms of arithmetic and root mean square average roughness values (Table 2 ).

The change in water contact angles of the pristine and crosslinked membranes is shown in Fig. 7. The PAI membrane is slightly hydrophilic displaying the initial and final contact angle values of $92-89^{\circ}$. On the other hand, after chemical crosslinking with PEI, the contact angle decreased by almost $20^{\circ}$ and the pristine membrane became more hydrophilic due to the presence of the amine group. The lower surface roughness and higher hydrophilic nature of PAI-PEI_pH10 membrane compared to the unmodified PAI membrane are other evidences of successful crosslinking between amine and imide groups.

\subsection{Molecular weight cut-off (MWCO) and pure water permeability (PWP)} of membranes

Four different neutral organic molecules glucose, sucrose, PEG 600 and PEG 1000 (embedded in Fig. 8) were used to determine MWCO of the PAI-PEI_pH 10 membrane. Fig. 8 shows the rejection of solutes as a function of their molecular weights. The MWCO and pore radius of the PAI-PEI_pH 10 membrane were determined to be $560 \mathrm{Da}$ and $0.568 \mathrm{~nm}$, respectively while its PWP was found as $4.77 \pm 0.45 \mathrm{~L} / \mathrm{m}^{2} \mathrm{hbar}$. The uncrosslinked pristine PAI membrane completely (100\%) rejected PEG 600 , however, the PWP of this membrane was found to be very low $\left(0.35 \pm 0.05 \mathrm{~L} / \mathrm{m}^{2} \mathrm{hbar}\right)$ due to its hydrophobic nature and lack of pore forming agent in the casting solution. The result demonstrates significant contribution of adding PEI into the coagulation bath not only for obtaining a positively charged membrane but also for increasing the PWP of the membrane to an acceptable level.

\subsection{Monovalent and multivalent ions separation performance of the membrane}

To show the salt separation efficiency of the PAI-PEI_pH 10 flat sheet NF membrane, four different salts $\left(\mathrm{MgCl}_{2}, \mathrm{CaCl}_{2}, \mathrm{Na}_{2} \mathrm{SO}_{4}, \mathrm{NaCl}\right)$ were used at the same concentration $(1000 \mathrm{ppm})$ and $\mathrm{pH}(\mathrm{pH}=3)$. The salt permeability of the PAI-PEI_pH 10 membrane was measured as $4.21 \pm 0.17 \mathrm{~L} / \mathrm{m}^{2}$ hbar. The experiments were carried out in acidic condition because protonation capacity of the membrane in acid medium is higher than in neutral condition as illustrated with zeta potential measurements. Thus, we wanted to benefit from Donnan exclusion (electrostatic repulsion) mechanism effectively in addition to size exclusion for rejection of ions. Fig. 9 shows that the salt retention order is $\mathrm{MgCl}_{2}>\mathrm{CaCl}_{2}>\mathrm{NaCl}>\mathrm{Na}_{2} \mathrm{SO}_{4}$. This order is consistent with Donnan exclusion theory and supports the zeta potential measurement that the membrane surface is the positively charged [37]. The PAI-PEI_PH 10 membrane displayed excellent rejection for positively charged multivalent ions $\left(95.6 \% \mathrm{Mg}^{2+}\right.$ and $\left.90.2 \% \mathrm{Ca}^{2+}\right)$ and moderate rejection for monovalent ions.

The application of positively charged NF membranes in acidic environment for the rejection of monovalent and divalent ions is limited. On the other hand, such an application may offer a solution in metal recovery from mine waste streams. Typical mine wastewater contains both divalent and monovalent ions, $\mathrm{Ca}^{+2}, \mathrm{SO}_{4}{ }^{-2}, \mathrm{~K}^{+}, \mathrm{Na}^{+}$and $\mathrm{Cl}^{-}$ [38] in addition to metal ions, thus, high selectivity for the separation of metals from salts is necessary to make NF an alternative separation process. Table 3 lists the selectivities of commercial and custom-made $\mathrm{NF}$ membranes for the separation of monovalent and divalent ions. Among the membranes listed in Table 3, our membrane has the highest selectivity in the recovery of $\mathrm{Mg}^{+2}$ ions from divalent salt $\mathrm{Na}_{2} \mathrm{SO}_{4}$. Although selectivity of the commercial membrane NTR-729HF for separating $\mathrm{NaCl}$ from $\mathrm{MgCl}_{2}$ is slightly higher than our membrane, their feed concentrations are much lower (293 and $238 \mathrm{ppm}$ for $\mathrm{NaCl}$ and $\mathrm{MgCl}_{2}$, respectively). If these low feed concentrations are used, we expect higher $\mathrm{Na}^{+} / \mathrm{Mg}^{+2}\left(\mathrm{NaCl} / \mathrm{MgCl}_{2}\right)$ selectivities for our membrane than the commercial NTR-729HF since the Donnan exclusion becomes more effective when the ion concentration in feed is low. It should also be noted that all salt rejection data reported by other groups were obtained at pressures higher than the pressure used in our study. Achieving high selectivity at low pressures is important to perform energy efficient separation, thus, to propose NF as an alternative process in the recovery of metals from salt containing acidic solutions.

In Table 4, the pure water permeabilities and MWCO values of

Table 3

The ion selectivities of various positively charged NF membranes at $\mathrm{pH} 3$.

\begin{tabular}{|c|c|c|c|c|c|c|c|c|}
\hline \multirow[t]{2}{*}{ Membrane } & \multirow{2}{*}{$\begin{array}{l}\text { Applied pressure } \\
\text { (bar) }\end{array}$} & \multirow[t]{2}{*}{ Feed concentration (ppm) } & \multicolumn{5}{|l|}{ Selectivity } & \multirow[t]{2}{*}{ Ref. } \\
\hline & & & $\begin{array}{l}\mathrm{Na}^{+} / \mathrm{Mg}^{2+} \\
\left(\mathrm{Na}_{2} \mathrm{SO}_{4} / \mathrm{MgCl}_{2}\right)\end{array}$ & $\begin{array}{l}\mathrm{Na}^{+} / \mathrm{Mg}^{2+} \\
\left(\mathrm{NaCl} / \mathrm{MgCl}_{2}\right)\end{array}$ & $\begin{array}{l}\mathrm{Na}^{+} / \mathrm{Ca}^{2+} \\
\left(\mathrm{Na}_{2} \mathrm{SO}_{4} / \mathrm{CaCl}_{2}\right)\end{array}$ & $\begin{array}{l}\mathrm{Na}^{+} / \mathrm{Ca}^{2+} \\
\left(\mathrm{NaCl} / \mathrm{CaCl}_{2}\right)\end{array}$ & $\begin{array}{l}\mathrm{SO}_{4}^{2-} / \mathrm{Cl}^{-} \\
\left(\mathrm{Na}_{2} \mathrm{SO}_{4} / \mathrm{NaCl}\right)\end{array}$ & \\
\hline PEI/TMC & 4 & 1000 & 3.4 & 3.1 & - & - & 1.1 & [19] \\
\hline PEI/TPC & & & 6.3 & 4.7 & - & - & 1.4 & \\
\hline UTC-60 & 3 & $\mathrm{NaCl}(293 \mathrm{ppm}) \mathrm{Na}_{2} \mathrm{SO}_{4}$ & 10 & 11 & 13.3 & 14.7 & 0.9 & [39] \\
\hline NTR-729HF & & $\begin{array}{l}(710 \mathrm{ppm}) \mathrm{CaCl}_{2}(277 \mathrm{ppm}) \\
\mathrm{MgCl}_{2}(238 \mathrm{ppm})\end{array}$ & - & 18.7 & - & 9.3 & - & \\
\hline NF-255 & 5 & $\mathrm{NaCl}(500 \mathrm{ppm}) \mathrm{Na}_{2} \mathrm{SO}_{4}$ & - & - & 2.7 & 2.8 & 0.98 & {$[40]$} \\
\hline NF-45 & 2.4 & $(500 \mathrm{ppm}) \mathrm{CaCl}_{2}(620 \mathrm{ppm})$ & - & - & 26 & 25 & 1.0 & \\
\hline NF-45 & $\begin{array}{l}\mathrm{NaCl}\left(10 \text { bar) } \mathrm{Na}_{2} \mathrm{SO}_{4}\right. \\
\text { (14 bar) } \mathrm{MgCl}_{2} \\
\text { (14 bar) }\end{array}$ & $\begin{array}{l}\mathrm{NaCl}(257 \mathrm{ppm}) \mathrm{Na}_{2} \mathrm{SO}_{4} \\
(2750 \mathrm{ppm}) \mathrm{MgCl}_{2}(1850 \mathrm{ppm})\end{array}$ & 1.1 & 1.9 & - & - & 0.6 & {$[41]$} \\
\hline PAI-PEI_pH 10 & 2 & 1000 & 20.9 & 15.2 & 9.4 & 6.8 & 1.3 & this work \\
\hline
\end{tabular}


Table 4

Comparison of the performances of different PAI based NF membranes.

\begin{tabular}{|c|c|c|c|c|}
\hline NF membrane & Preparation procedure & MWCO (Da) & PWP (L/m² har) & Ref. \\
\hline PAI-PEI hollow fiber (PEI_2K) & Chemical modification & 1278 & 6.37 & [34] \\
\hline PAI-PEI hollow fiber (PEI_20K) & & 1278 & 4.85 & \\
\hline PAI-PEI hollow fiber (PEI_60K) & & 912 & 3.58 & \\
\hline PAI-PEI hollow fiber (PEI_800) & Chemical modification & - & 2.25 & [43] \\
\hline P84-PEI hollow fiber (PEI_60K) & Chemical modification & - & 0.98 & [27] \\
\hline P84-PEI flat sheet (PEI_25K) & Chemical modification & - & 3.6 & [29] \\
\hline PAI-PEI flat sheet (PEI_800) & Chemical modification & - & 4.58 & {$[35]$} \\
\hline PES-PEI ${ }_{5 \%}$ hollow fiber (PEI_750K) & Single step preparation & 700 & 0.4 & [42] \\
\hline PES-PEI $_{10 \%}$ hollow fiber (PEI_750K) & & 1040 & 2.0 & \\
\hline PAI-PEI flat sheet (PEI_25K) & Single step preparation & 560 & 4.77 & This work \\
\hline
\end{tabular}

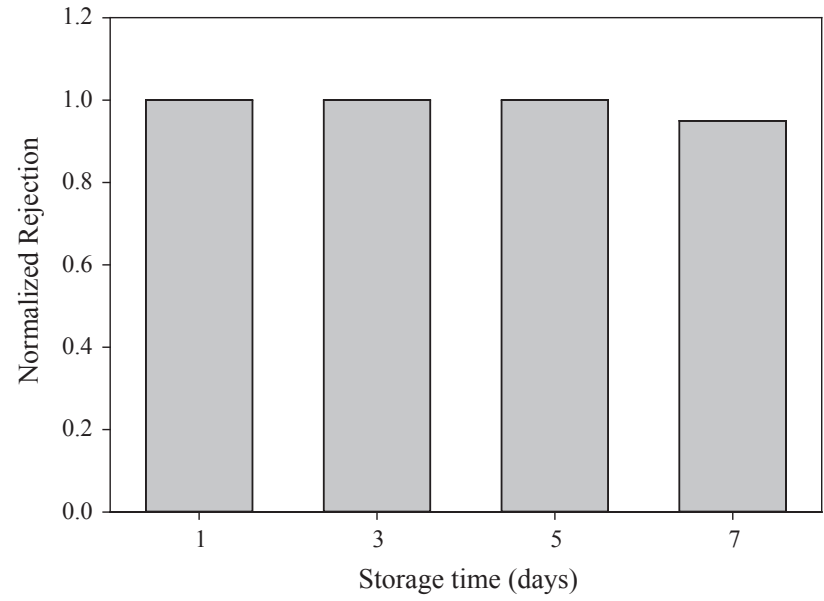

Fig. 10. Chemical stability performance of the PAI membrane crosslinked with PEI at $\mathrm{pH} 10$.

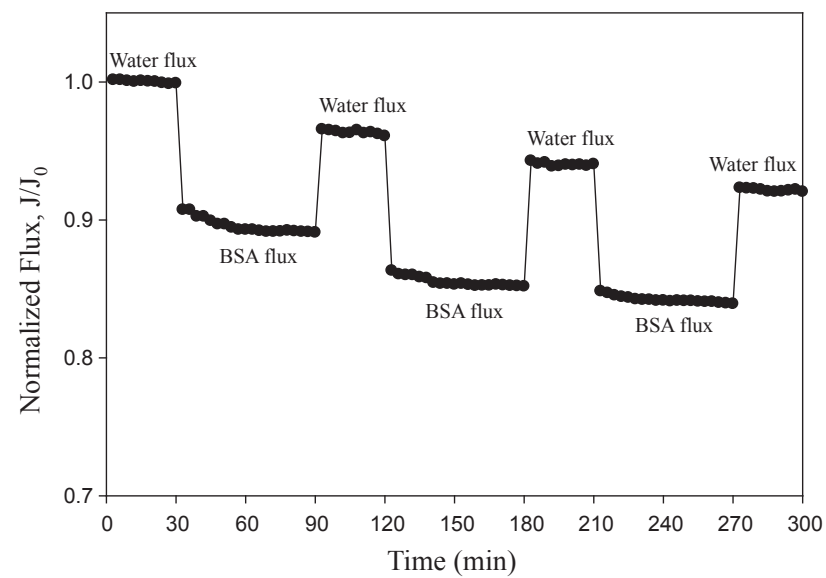

Fig. 11. Antifouling performance of the PAI membrane crosslinked with PEI at pH 10.

different PAI based hollow fiber and flat sheet membranes are listed. Although our membrane was prepared in a single step, its MWCO is half of the PAI_PEI hollow fiber membranes prepared in two steps [34] while the PWP values are similar. Thus, with our high flux membrane it is possible to recover smaller molecular weight valuable neutral compounds. Gherasim et al. [42] manufactured their hollow fiber membranes in a single step, however, the PWP of these membranes are lower and MWCO values are higher than our membrane.

\subsection{Chemical stability and antifouling property of the membrane}

Industrial applications of nanofiltration in acidic environment are

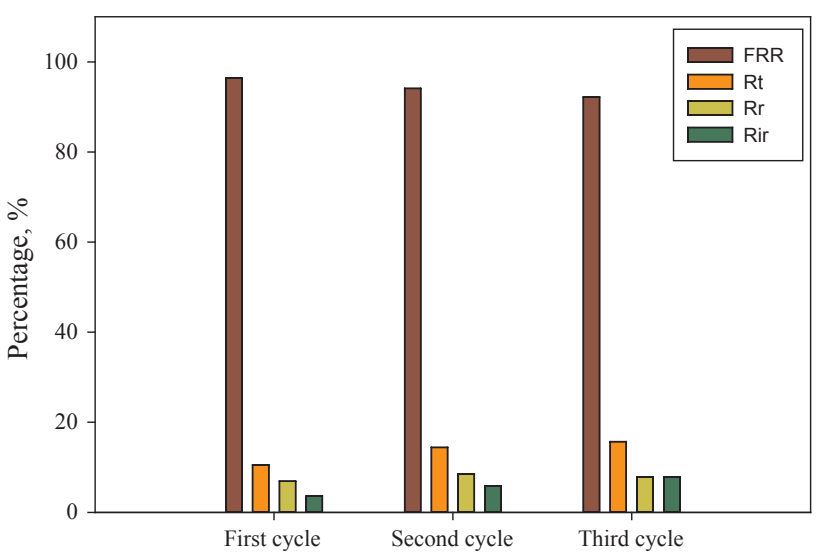

Fig. 12. Fouling resistances and flux recovery ratio of the PAI membrane crosslinked with PEI at $\mathrm{pH} 10$.

still limited due to insufficient acid resistance of commercial membranes. To evaluate the potential of the PAI_PEI NF membrane for the treatment of acidic solutions, the membrane was exposed to $\mathrm{HCl}$ acid solution at $\mathrm{pH} 3$ up to 7 days. The change in the structure of the membrane was checked by measuring its PEG 1000 rejection. Fig. 10 shows the rejection data normalized with respect to the PEG 1000 rejection value of fresh membrane not treated with $\mathrm{HCl}$ solution. As seen from the data, there is no significant change in the rejection values which demonstrated that our membrane was not affected from highly acidic condition. Although transport and rejection properties of the PAI based flat sheet NF membrane were measured in previous studies, its chemical stability was not tested.

We tested antifouling performance of the optimized membrane using $1 \mathrm{~g} / \mathrm{L}$ BSA solution. Fig. 11 shows the change of normalized BSA flux up to $3 \mathrm{~h}$ through PEI crosslinked membrane and Fig. 12 demonstrates the flux recovery ratios and fouling resistances. FRR values at the end of first, second and third cycles were determined as $96.4 \%$, $94.1 \%$ and $92.2 \%$, respectively. High flux recoveries can be attributed to limited hydrophobic-hydrophobic interactions between the foulant BSA and the membrane surface due to the presence of hydrophilic PEI. In the first two cycles, BSA fouling is mostly reversible while in the third cycle reversible and irreversible fouling resistances are similar in magnitude. The decrease in flux recoveries with time is due to increased irreversible BSA deposition.

\section{Conclusion}

In this study, a facile approach is proposed for the fabrication of PAI based positively charged flat sheet NF membranes. In this approach, PEI dissolved in a coagulation bath makes in situ chemical crosslinking with PAI during the phase inversion. Alkaline $\mathrm{pH}$ in the coagulation bath enhanced the positive charge density of the membrane when compared to acidic and neutral conditions. Although not investigated in this 
study, the positive charge density of the membrane can be further adjusted by changing the concentration of PEI and immersion time in the PEI containing coagulation bath. The obtained membrane showed good performance in terms of pure water permeability (PWP) and removal of multivalent ions such as $\mathrm{Ca}^{+2}$ and $\mathrm{Mg}^{+2}$ and displayed higher selectivity in the recovery of magnesium from salt containing acidic solution than commercial membranes. In addition, the membrane has shown no significant change in its stability when stored in acidic solution. Thus, we can conclude that the membrane has a great potential in the treatment of acidic mine wastewater and in the recovery of valuable cationic metals without any need for $\mathrm{pH}$ adjustment. Furthermore, due to its chemical stability, it could also be used for treating acidic wastewater generated e.g. from pharmaceutical industry. The PAI membrane crosslinked with PEI at pH 10 also exhibited good performance in terms of fouling resistance and flux recovery ratio after $3 \mathrm{~h}$ BSA filtration. The facile approach proposed in this study can be used for fabricating positively charged PAI based NF membranes due to its various advantageous such as single step preparation without need for any pore former, use of commercially available polymers and easy scalability.

\section{Acknowledgement}

One of the authors, Aydın Cihanoğlu, was supported by the Scientific and Technological Research Council of Turkey (TÜBITAK) with $(2211 / \mathrm{E})$ National $\mathrm{PhD}$ Scholarship programme. We also would like to thank the Material Research Center, Biotechnology and Bioengineering Application Research Center and Environmental Research Center at the İzmir Institute of Technology for their kind help and technical support.

\section{References}

[1] W.R. Bowen, A.W. Mohammad, N. Hilal, Characterisation of nanofiltration membranes for predictive purposes - use of salts, uncharged solutes and atomic force microscopy, J. Membr. Sci. 126 (1997) 91-105.

[2] J. Lin, C.Y. Tang, C. Huang, Y.P. Tang, W. Ye, J. Li, J. Shen, R. Van den Broeck, J. Van Impe, A. Volodin, C. Van Haesendonck, A. Sotto, P. Luis, B. Van der Bruggen, A comprehensive physico-chemical characterization of superhydrophilic loose nanofiltration membranes, J. Membr. Sci. 501 (2016) 1-14.

[3] J. Lin, W. Ye, H. Zeng, H. Yang, J. Shen, S. Darvishmanesh, P. Luis, A. Sotto, B. Van der Bruggen, Fractionation of direct dyes and salts in aqueous solution using loose nanofiltration membranes, J. Membr. Sci. 477 (2015) 183-193.

[4] W. Ye, J. Lin, R. Borrego, D. Chen, A. Sotto, P. Luis, M. Liu, S. Zhao, C.Y. Tang, B. Van der Bruggen, Advanced desalination of dye/ $\mathrm{NaCl}$ mixtures by a loose nanofiltration membrane for digital ink-jet printing, Sep. Purif. Technol. 197 (2018) 27-35.

[5] J. Lin, C.Y. Tang, W. Ye, S.P. Sun, S.H. Hamdan, A. Volodin, C. Van Haesendonck, A. Sotto, P. Luis, B. Van der Bruggen, Unraveling flux behavior of superhydrophilic loose nanofiltration membranes during textile wastewater treatment, J. Membr. Sci. 493 (2015) 690-702.

[6] J. Zhu, A. Uliana, J. Wang, S. Yuan, J. Li, M. Tian, K. Simoens, A. Volodin, J. Lin, K. Bernaerts, Y. Zhang, B. Van der Bruggen, Elevated salt transport of antimicrobial loose nanofiltration membranes enabled by copper nanoparticles via fast bioinspired deposition, J. Mater. Chem. A 4 (2016) 13211-13222.

[7] S. Zhao, C. Ba, Y. Yao, W. Zheng, J. Economy, P. Wang, Removal of antibiotics using polyethyleneimine cross-linked nanofiltration membranes: Relating membrane performance to surface charge characteristics, Chem. Eng. J. 335 (2018) 101-109.

[8] S. Cheng, D.L. Oatley, P.M. Williams, C.J. Wright, Characterisation and application of a novel positively charged nanofiltration membrane for the treatment of textile industry wastewaters, Water Res. 46 (2012) 33-42.

[9] H.-Z. Zhang, Z.-L. Xu, H. Ding, Y.-J. Tang, Positively charged capillary nanofiltration membrane with high rejection for $\mathrm{Mg}^{2+}$ and $\mathrm{Ca}^{2+}$ and good separation for $\mathrm{Mg}^{2+}$ and $\mathrm{Li}^{+}$, Desalination 420 (2017) 158-166.

[10] A. Pal, T.K. Dey, R.C. Bindal, Intrinsic dependence of hydrophilic and electrokinetic features of positively charged thin film composite nanofiltration membranes on molecular weights of poly(ethyleneimine)s, Polymer 93 (2016) 99-114.

[11] T. Wang, Y. Yang, J. Zheng, Q. Zhang, S. Zhang, A novel highly permeable positively charged nanofiltration membrane based on a nanoporous hyper-crosslinked polyamide barrier layer, J. Membr. Sci. 448 (2013) 180-189.

[12] W. Li, C. Shi, A. Zhou, X. He, Y. Sun, J. Zhang, A positively charged composite nanofiltration membrane modified by EDTA for $\mathrm{LiCl} / \mathrm{MgCl}_{2}$ separation, Sep. Purif. Technol. 186 (2017) 233-242.

[13] H. Wang, Q. Zhang, S. Zhang, Positively charged nanofiltration membrane formed by interfacial polymerization of 3,3'5,5'-biphenyl tetraacyl chloride and piperazine on a poly(acrylonitrile) (PAN) support, J. Membr. Sci. 378 (2011) 243-249.

[14] X. Bai, Y. Zhang, H. Wang, H. Zhang, J. Liu, Study on the modification of positively charged composite nanofiltration membrane by $\mathrm{TiO}_{2}$ nanoparticles, Desalination
313 (2013) 57-65.

[15] D. Wu, Y. Huang, S. Yu, D. Lawless, X. Feng, Thin film composite nanofiltration membranes assembled layer-by-layer via interfacial polymerization from polyethyleneimine and trimesoyl chloride, J. Membr. Sci. 472 (2014) 141-153.

[16] F.-Y. Zhao, Y.-L. Ji, X.-D. Weng, Y.-F. Mi, C.-C. Ye, Q.-F. An, C.-J. Gao, High-flux positively charged nanocomposite nanofiltration membranes filled with poly(dopamine) modified multiwall carbon nanotubes, ACS Appl. Mater. Interf. 8 (2016) 6693-6700.

[17] W. Fang, L. Shi, R. Wang, Interfacially polymerized composite nanofiltration hollow fiber membranes for low-pressure water softening, J. Membr. Sci. 430 (2013) 129-139.

[18] X. Wei, S. Wang, Y. Shi, H. Xiang, J. Chen, B. Zhu, Characterization of a positively charged composite nanofiltration hollow fiber membrane prepared by a simplified process, Desalination 350 (2014) 44-52.

[19] Y.-C. Chiang, Y.-Z. Hsub, R.-C. Ruaan, C.-J. Chuang, K.-L. Tung, Nanofiltration membranes synthesized from hyperbranched polyethyleneimine, J. Membr. Sci. 326 (2009) 19-26.

[20] J. Wang, J. Zhu, M.T. Tsehaye, J. Li, G. Dong, S. Yuan, X. Li, Y. Zhang, J. Liu, B. Van der Bruggen, High flux electroneutral loose nanofiltration membranes basen on rapid deposition of polydopamine/polyethyleneimine, J. Mater. Chem. A 5 (2017) $14847-14857$.

[21] Y. Yao, C. Ba, S. Zhao, W. Zheng, J. Economy, Development of a positively charged nanofiltration membrane for use in organic solvents, J. Membr. Sci. 520 (2009) $832-839$.

[22] Y. Zheng, G. Yao, Q. Cheng, S. Yu, M. Liu, C. Gao, Positively charged thin-film composite hollow fiber nanofiltration membrane for the removal of cationic dyes through submerged filtration, Desalination 328 (2013) 42-50.

[23] J. Zhu, Q. Zhang, J. Zheng, S. Hou, H. Mao, S. Zhang, Green fabrication of a positively charged nanofiltration membrane by grafting poly(ethylene imine) onto a poly(arylene ether sulfone) membrane containing tertiary amine groups, J. Membr. Sci. 517 (2016) 39-46.

[24] Y. Ji, Q. An, Q. Zhao, H. Chen, C. Gao, Preparation of novel positively charged copolymer membranes for nanofiltration, J. Membr. Sci. 376 (2011) 254-265.

[25] M. Li, Z. Lv, J. Zheng, J. Hu, C. Jiang, M. Ueda, X. Zhang, L. Wang, Positively charged nanofiltration membrane with dendritic surface for toxic element removal, ACS Sustain. Chem. Eng. 5 (2017) 784-792.

[26] K. Goh, L. Setiawan, L. Wei, R. Si, A.G. Fane, R. Wang, Y. Chen, Graphene oxide as effective selective barriers on a hollow fiber membrane for water treatment process, J. Membr. Sci. 474 (2015) 244-253.

[27] J. Gao, S.-P. Sun, W.-P. Zhu, T.-S. Chung, Polyethyleneimine (PEI) cross-linked P84 nanofiltration (NF) hollow fiber membranes for $\mathrm{Pb}^{2+}$ removal, J. Membr. Sci. 452 (2014) 300-310.

[28] R. Zhang, Y. Su, X. Zhao, Y. Li, J. Zhao, Z. Jiang, A novel positively charged composite nanofiltration membrane prepared by bio-inspired adhesion of polydopamine and surface grafting of poly(ethylene imine), J. Membr. Sci. 470 (2014) 9-17.

[29] C. Ba, J. Langer, J. Economy, Chemical modification of P84 copolyimide membranes by polyethyleneimine for nanofiltration, J. Membr. Sci. 327 (2009) 49-58.

[30] Y. Cui, Z.-K. Yao, K. Zheng, S.-Y. Du, B.-K. Zhu, L.-P. Zhu, C.-H. Du, Positivelycharged nanofiltration membrane formed by quaternization and cross-liking of blend PVC/P(DMA-co-MMA) precursors, J. Membr. Sci. 492 (2015) 187-196.

[31] L. Yu, J. Deng, H. Wang, J.-D. Liu, Y. Zhang, Improved salts transportation of a positively charged loose nanofiltration membrane by introduction of poly(ionic liquid) functionalized hydrotalcite nanosheets, ACS Sustain. Chem. Eng. 4 (2016) 3292-3304.

[32] Q. Zhang, H. Wang, S. Zhang, L. Dai, Positively charged nanofiltration membrane based on cardo poly(arylene ether sulfone) with pendant tertiary amine groups, J. Membr. Sci. 375 (2011) 191-197.

[33] L. Yu, Y. Zhang, Y. Wang, H. Zhang, J. Liu, High flux, positively charged loose nanofiltration membrane by blending with poly(ionic liquid) brushes grafted silica spheres, J. Hazard. Mater. 287 (2015) 373-383.

[34] S.P. Sun, T.S. Chung, Hyperbranched polyethyleneimine induced cross-linking of polyamide-imide nanofiltration hollow fiber membranes for effective removal of ciprofloxacin, Environ. Sci. Technol. 45 (2011) 4003-4009.

[35] C. Qiu, L. Setiawan, R. Wang, C.Y. Tang, A.G. Fane, High performance flat sheet forward osmosis membrane with an NF-like selective layer on a woven fabric embedded substrate, Desalination 287 (2012) 266-270.

[36] K.J. Kim, A.G. Fane, M. Nystrom, A. Pihlajamaki, W.R. Bowen, H. Mukhtar, Evaluation of electroosmosis and streaming potential for measurement of electric charges of polymeric membranes, J. Membr. Sci. 116 (1996) 149-159.

[37] J.M.M. Peeters, J.P. Boom, M.H.V. Mulder, H. Strathmann, Retention measurements of nanofiltration membranes with electrolyte solutions, J. Membr. Sci. 145 (1998) 199-209.

[38] M. Mullett, R. Fornarelli, D. Ralph, Nanofiltration of mine water: Impact of feed pH and membrane charge on resource recovery and water discharge, Membranes 4 (2014) 163-180.

[39] S. Kim, H. Ozaki, J. Kim, Effect of pH on the rejection of inorganic salts and organic compound using nanofiltration membrane, Korean J. Chem. Eng. 23 (2006) 28-33.

[40] S. Szoke, G. Patzay, L. Weiser, Characteristics of thin-film nanofiltration membranes at various pH-values, Desalination 151 (2003) 123-129.

[41] Y. Xu, R.E. Lebrun, Investigation of the solute separation by charged nanofiltration membrane: effect of pH, ionic strength and solute type, J. Membr. Sci. 158 (1999) 93-104.

[42] C.V. Gherasim, T. Luelf, H. Roth, M. Wessling, Dual-charged hollow fiber membranes for low-pressure nanofiltration based on polyelectrolyte complexes: one-step fabrication with tailored functionalities, ACS Appl. Mater. Interf. 8 (2016) 19145-19157.

[43] L. Setiawan, R. Wang, K. Li, A.G. Fane, Fabrication of novel poly(amide-imide) forward osmosis hollow fiber membranes with a positively charged nanofiltrationlike selective layer, J. Membr. Sci. 369 (2011) 196-205. 